\title{
EL RECONOCIMIENTO DEL DERECHO A LA SALUD DE UN MENOR DISCAPACITADO A TRAVÉS DE LA CAUTELAR INNOMINADA
}

\section{THE RECOGNITION OF THE RIGHT TO HEALTH OF A DISABLED MINOR THROUGH UNNAMED PRECAUTIONARY}

\section{Valeria de las Mercedes Sola'}

DOI: https://doi.org/10.37767/2591-3476(2020)33

\section{Comentario a}

S. I. c/ SAMI s/ amparo ley 16.986 s/ inc. apelación s/ inc. Apelación

Cámara Federal de Apelaciones de Mar del Plata

(Poder Judicial de la Nación)

\section{Disponible en}

https://bit.ly/2Yo3zVR

\section{RESUMEN:}

En el siguiente artículo se analiza la causa "S. I. c/ SAMI s/ amparo Ley 16986 s/ inc. apelación", en la cual el día 12 de febrero de 2019, la Cámara Federal de Apelaciones de la ciudad de Mar del Plata, confirmó la resolución del tribunal de grado que hizo lugar a una la medida cautelar innovativa. A través de la medida se ordenaba a la empresa de medida prepaga la cobertura la cobertura del $100 \%$ de la cirugía de cierre de comunicación interventricular y ductus arterio venoso, con la correspondiente internación, como de los tratamientos de rehabilitación posteriores a la cirugía y medicación que se le recete al menor con discapacidad.

\begin{abstract}
The following article analyzes the cause "S. I. c / SAMI s / amparo Law 16986 s / inc. appeal ", in which on February 12, 2019, the Federal Court of Appeals of the city of Mar del Plata, confirmed the resolution of the grade court that led to an innovative precautionary measure. Through the measure, the prepaid measure company was ordered to cover $100 \%$ of the interventricular communication and ductus arteriovenous closure surgery, with the corresponding hospitalization, as well as the rehabilitation treatments after surgery and medication. that the minor with a disability is prescribed.
\end{abstract}


PALABRAS CLAVE: Derecho a la salud; Persona menor con discapacidad; Tutela judicial efectiva; Medida cautelar innovativa.

KEY WORDS: Right to health; Minor person with a disability; Innovative precautionary measure; Effective judicial protection.

\section{Introducción}

A los fines de introducirnos en el desarrollo del presente comentario, es necesario en primer lugar explicar que "el derecho a la vida es el derecho básico sobre el que se sustentan todo el elenco de derechos que conocemos. Sin este derecho, sería imposible hacer valer cualquier otro. Íntimamente ligado a la vida, para poder gozarla en plenitud, se encuentra el derecho a la salud que, por su importancia crucial en el sistema jurídico, ha ido teniendo más relieve con el paso de los años, adquiriendo cada vez mayor autonomía"(Zalazar y Carranza, 2019, 11).

Sabido es que para el reconocimiento de estos derechos fundamentales no sólo se necesita de una normativa que lo establezca, sino también de que esas declaraciones de derechos se hagan operativas a través de los carriles o vías pertinentes.

En este contexto, cabe recordar que incumbe a los jueces la búsqueda de soluciones congruentes con la urgencia ínsita en los temas de asistencia integral de la discapacidad, debiendo encausar los trámites por los carriles expeditivos y evitar que el rigor de las formas conduzca a la frustración de derechos que cuentan con tutela constitucional. ${ }^{2}$ Es que no puede perderse de vista que toda persona que se encuentre en situación de vulnerabilidad es titular de una protección especial.

Por otra parte, se ha expresado que: "La vulnerabilidad tiene, por tanto, una dimensión de susceptibilidad al daño, condicionada por factores intrínsecos y extrínsecos, anclada en la radical fragilidad del ser humano, pero sin duda atribuible en buena medida a elementos sociales y ambientales. El énfasis puesto en lo relacional, lo contextual y lo procesual, permite considerar que la vulnerabilidad, aun siendo intrínseca al ser humano, no es una característica estable e inmutable, antes bien es dependiente, al menos en parte, de factores que pueden cambiarse, en los que se puede intervenir. De ahí que ésta sea la clave que sustenta la obligación moral de una acción, preventiva, curativa, social, económica, o de cualquier otra índole, que pueda minimizar, paliar o evitar estas condiciones favorables al daño, estos espacios de vulnerabilidad" (Feito, 2007).

\section{Síntesis de la causa}

En el marco de una acción de amparo, el Juzgado Federal n. ${ }^{\circ} 2$, Sec. $n .^{\circ} 1$ de la ciudad de Mar del Plata resolvió hacer lugar a la medida cautelar solicitada por la amparista, en representación de su hijo menor de edad -persona con discapacidad-y en consecuencia, ordenó a la demandada otorgar la cobertura del 100\% de la cirugía de cierre de comunicación interventricular (CIV) y ductus arterio venoso, con la correspondiente internación, así como la cobertura de los tratamientos de rehabilitación posteriores a la cirugía y medicación que se le recete al menor. 
Frente al dictado de la orden cautelar en resguardo de las necesidades de salud del menor amparista, la accionada interpuso recurso de apelación. Explicó que la agravió el dictado de la medida dispuesta, en razón de la inexistencia de verosimilitud en el derecho, puesto que su mandante no tuvo posibilidad de auditar el pedido médico.

A su vez, alegó que no se encontraba acreditada en la causa, la necesidad que el niño se opere en el establecimiento indicado por el amparista. Por otro lado, sostuvo la falta de peligro en la demora. Asimismo, señaló que con la cautelar ordenada se ha producido la violación a los derechos de defensa en juicio y debido proceso. Finalmente, y en forma subsidiaria solicitó se establezca un tope de cobertura.

La Cámara Federal de Apelaciones de la ciudad de Mar del Plata, el día 12 de febrero de 2019, confirmó la sentencia que acogió la medida cautelar, pues entendió que se debían adoptar medidas que garanticen el derecho a la salud, a fin de asegurarle al menor una calidad de vida digna como también un desarrollo que no vulnere sus derechos humanos fundamentales por su padecimiento, ponderando el Interés Superior del Niño.

\section{Análisis preliminar del caso: Derechos involucrados.}

En el caso bajo análisis ${ }^{3}$, se puede visualizar que la empresa de medicina prepaga discrepa con la solución propiciada por el tribunal que decide en primera instancia admitir la cautelar solicitada a favor de una persona menor de edad discapacitada. Así, la apelante -demandada en la acción de amparo- cuestiona que la decisión del aquo que dispone admitir la cautelar y le ordena otorgar cobertura integral al amparista, resulta violatoria de derechos fundamentales tales como: "defensa en juicio" y "debido proceso".

Sin embargo, la Cámara al entrar a analizar el caso en cuestión, destaca la necesidad de valorar la trascendencia de los derechos que se encuentran comprometidos para poder emitir una solución ajustada a derecho de acuerdo a las circunstancias de la causa y resolver, en definitiva, si la cobertura de la cirugía, internación, tratamientos de rehabilitación y medicación concedida al menor con discapacidad por el tribunal de grado afectaba arbitrariamente los derechos invocados por la demandada.

En el contexto referenciado, la Cámara destaca que ese análisis requiere tener presente el "derecho a la salud", "a una buena calidad de vida" y "asistencia médica adecuada". A su vez, explica que en tal valoración, además, se debe ponderar el "Interés Superior del Niño" por tratarse de una persona menor de edad.

Frente a ello, resulta necesario, en primer lugar, visualizar los derechos involucrados en forma cautelar y, en segundo lugar, interpretar la normativa aplicada a la cuestión para luego poder dimensionar la trascendencia y justeza que tiene la resolución traída a consideración.

\section{Situación vital del menor con discapacidad}

Como pudimos observar, la resolución que estamos analizando introduce en forma cautelar una cuestión controvertida muy crítica, pues se trata de un menor discapacitado necesitado de una urgente tutela que le permita contar con los recursos y los medios necesarios para la realización de su cirugía, internación, tratamientos de rehabilitación posteriores a la misma y medicación, que de otro modo no podría proveérselos. 
De este modo, el tribunal debía determinar si correspondía confirmar o rechazar la resolución que obliga a la empresa de medicina prepaga la cobertura integral de las prestaciones prescriptas para el niño que posee discapacidad. Para ello, resultaba imprescindible la valoración de los derechos involucrados en el caso, lo cual implicaba que se tuviera en mira la situación vital del menor involucrado.

A los fines de dimensionar los contornos e importancia de la cuestión, es oportuno recordar que el derecho a la salud -máxime cuando se trate de enfermedades graves y de personas que padecen discapacidad- se encuentra íntimamente relacionado con el derecho a la vida que está reconocido por la Constitución y por los tratados internacionales que tienen jerarquía constitucional (art. 75 inc. 22 de la Ley Suprema), por lo que la autoridad pública tiene la obligación impostergable de garantizar ese derecho con acciones positivas, sin perjuicio de las obligaciones que deban asumir en su cumplimiento las jurisdicciones locales, las obras sociales, o las entidades de las llamada medicina prepaga ${ }^{4}$.

En tal sentido, cabe recordar que en cualquier caso en el que esté de por medio la salud, $y$, con ello, el derecho a la vida de las personas, debe partirse necesariamente de un pormenorizado análisis de las circunstancias vitales particulares que subyacen al planteo, en aras de dotar de equidad a la solución que se procure, por cuanto, lo justo judicial es lo que, acorde a derecho, resulta prudente y razonable en ese caso en particular y no a cualquier otro ${ }^{5}$.

En esa dirección, se encamina la Cámara cuando indica se debe valorar la relevancia que tiene el derecho a la salud, a una buena calidad de vida y asistencia médica adecuada, pero analizando estos derechos desde la situación de vida del niño discapacitado, su padecimiento, necesidades, y teniendo como norte su interés superior.

En efecto, la Cámara Federal de Apelaciones resalta la necesidad de adoptar medidas que garanticen el derecho a la salud, a fin de poder asegurarle al menor una calidad de vida digna como también un desarrollo que no vulnere sus derechos humanos fundamentales por su padecimiento, ponderando -principalmente- el Interés Superior del Niño consagrado normativamente. Es que, como se precisa, es claro que sí hay riesgo y peligro de daño -a la salud o a una buena calidad de vida-, es inminente otorgar seguridad antes y no después de su generación y contar con las fuentes de financiamiento para abordar el padecimiento, que sean oportunas y funcionales, y a cargo de quién lo provoca. A su vez, el derecho a una buena calidad de vida tiene un papel central en la sistemática de los derechos humanos, siendo la asistencia médica un aspecto fundamental de la misma. ${ }^{6}$

Repárese que la cuestión que estamos abordando trata de una situación que afectada el derecho a la salud de un menor discapacitado -y con el ello el derecho a tener una buena calidad de vida- como consecuencia de la patología que padece. Y que, frente a ello, debió acudir a la justicia para obtener una urgente tutela que le permita obtener la asistencia médica necesaria -cirugía, tratamientos y medicación- para poder garantizar sus derechos esenciales. 
En virtud de lo expresado, no existen dudas en relación a que los derechos comprometidos en este caso, se encuentran inescindiblemente unidos con el derecho a la vida, pues todo ser humano tiene derecho al disfrute del más alto nivel posible de salud que le permita vivir su vida dignamente.

En tal sentido, y a mayor abundamiento, la jurisprudencia de nuestro Máximo Tribunal nacional ha hecho especial hincapié en que la protección y la asistencia universal de la infancia discapacitada constituye una política pública, en cuanto a que la niñez, además de la especial atención por parte de quienes están directamente encargados de su cuidado, requiere también la de los jueces y de la sociedad toda, con lo cual, la consideración primordial de aquel interés orienta y condiciona la decisión jurisdiccional, con singular énfasis en aquellos menores aquejados por impedimentos físicos o mentales, debiendo ser custodiado con acciones positivas por todos los departamentos gubernamentales ${ }^{7}$.

No obstante, se debe reparar que la Cámara interviniente, a fin de poder adoptar y fundar una resolución que brindara una solución justa a la realidad planteada, debió analizar e interpretar la normativa nacional e internacional referida a los derechos en juego. Es que, no debemos perder de vista la obligación que tienen los magistrados buscar la solución que sea congruente con la urgencia planteada y que tenga en mira la asistencia integral a la discapacidad que posee el menor, evitando, de este modo, la frustración de sus derechos elementales.

\section{El derecho a la salud del menor con discapacidad como derecho humano esen- cial. Reconocimiento normativo.}

Se ha expresado, con gran sustento, que las prestaciones cuya cobertura se demandan a través de la acción de amparo forman parte de un derecho personalísimo fundamental de rango constitucional, y consagrado a nivel internacional en numerosas normas convencionales que ostentan jerarquía constitucional conforme lo dispuesto por el art. 75, inc. 22, de la $\mathrm{CN}^{8}$.

En esta línea, nuestro Estado Nacional ha ratificado dos instrumentos internacionales de derechos humanos que son aplicados por los magistrados intervinientes para resolver la cuestión; A saber:

1) La Convención Internacional sobre Derechos de las Personas con Discapacidad y su Protocolo Facultativo (Ley n. ${ }^{\circ}$ 26378), cuyo propósito es promover, proteger y asegurar el goce pleno y en condiciones de igual de todos los seres humanos y libertades fundamentales por todas las personas con discapacidad, así como promover el respeto de su dignidad inherente;

2) La Convención Interamericana para la Eliminación de Todas Formas de Discriminación Contra las Personas con Discapacidad (Ley n. ${ }^{\circ} 25280$ ), a través de la cual se busca prevenir y eliminar todas las formas de discriminación contra las personas con discapacidad y propiciar su plena integración a la sociedad. Esta considera persona con discapacidad a quienes tengan dificultades físicas, mentales, intelectuales o sensoriales a largo plazo, las que al interactuar con diversas barreras, puedan impedir su participación plena y efectiva en la sociedad en igualdad de condiciones con las demás. Además, se

7 Cfr. CSJN, Fallos 329:5139 y 332:1394, entre muchos otros.

8 TSJ de Córdoba, en autos “U., M. D. c/ Administración Provincial del Seguro de Salud (APROSS) - Amparo (Ley 4915) - Recurso de Apelación”. Auto n. 51 de fecha 12/8/2019. 
reconoce el respeto a la dignidad inherente, la autonomía individual, independencia de las personas y la participación e inclusión plena y efectiva en la sociedad (art. 1 y 3).

A través de estos instrumentos se vislumbra un fuerte compromiso del Estado Argentino respecto a la necesidad de adoptar medidas destinadas a lograr la igualdad de oportunidades para las personas con discapacidad.

Por su parte, la Convención Interamericana para la Eliminación de todas las formas de discriminación contra las personas con discapacidad dispone que las personas con discapacidad tienen derecho a gozar del más alto nivel posible de salud sin discriminación por motivos de discapacidad y que se deberán adoptar las medidas pertinentes para asegurar el acceso de las personas con discapacidad a servicios de salud, incluida la rehabilitación relacionada con la salud (art. 25).

Luego, y en relación a la rehabilitación, el Estado se comprometió a adoptar medidas efectivas y pertinentes para que las personas con discapacidad puedan lograr y mantener la máxima independencia, capacidad física, mental, social y vocacional, y la inclusión y participación plena en todos los aspectos de la vida. A tal fin, estipuló que el Estado debe organizar, intensificar y ampliar los servicios y programas generales de habilitación y rehabilitación, en particular en los ámbitos de la salud, el empleo, la educación y los servicios sociales, para apoyar su participación e inclusión en la comunidad y en todos los ámbitos de la sociedad (art. 26).

Resulta importante destacar que esta protección constitucional y convencional del derecho a la salud adquiere una mayor dimensión cuando su titularidad es ejercida por una persona que se encuentra en estado de vulnerabilidad, como sucede cuando se trata de un niño con discapacidad que requiere de una empresa de medicina prepaga la urgente tutela de sus derechos.

En el mismo sentido, el art. 18 del Protocolo Adicional a la Convención Americana en materia de Derechos Económicos, Sociales y Culturales -Protocolo de San Salvador-, otorga protección para minusválidos y dispone que "toda persona afectada por una disminución de sus capacidades físicas o mentales tiende derecho a recibir una atención especial con el fin de alcanzar el máximo desarrollo de su personalidad".

En similares términos se pronuncia, la Ley Nacional n. ${ }^{\circ} 22431$ que instituyó un sistema de protección integral de las personas con discapacidad tendientes a abarcar todos los aspectos relativos a su situación dentro de la sociedad, a los fines de conceder a quienes se encontraren en esas condiciones, franquicias y estímulos que les permitan, en la medida de lo posible, neutralizar la desventaja que la discapacidad les provoca (art. 1).

Por su parte, la Ley n. ${ }^{\circ} 4901$-denominada "Sistema Único de Prestaciones Básicas en Habilitación y Rehabilitación Integral a favor de Personas con Discapacidad"--, que garantiza una cobertura integral a sus necesidades y requerimientos, contemplando acciones de prevención, asistencia, promoción y protección de la personas con discapacidad. Esta protección contempla prestaciones preventivas (art. 14), de rehabilitación (art. 15), asistenciales (art. 18), entre otras.

Pero en el caso en comentario, todo este plexo tuitivo de las personas que padecen 
discapacidad, además, se encuentra reforzado en función de lo establecido por la Convención de los Derechos del Niño incorporada con jerarquía constitucional (art. 75, inc. 22, CN). Esta Convención, establece la obligación de adoptar medidas especiales de protección en materia de salud y seguridad social, para que el niño mental o físicamente impedido pueda disfrutar de una vida plena y decente en condiciones que aseguren su dignidad, que le permita llegar a bastarse a sí mismo y faciliten su activa participación en la comunidad (arts. 23, 24 y 26).

De acuerdo a lo desarrollado, se puede advertir que, existen mandatos normativos concretos que imponen al Estado la obligación de garantizar la cobertura integral de las prestaciones requeridas por la progenitora del menor discapacitado.

Como corolario de lo reseñado y con la finalidad de hacer efectiva la protección integral del menor, es que el Estado debe adoptar las medidas necesarias para lograr la plena realización de tales derechos, debiendo considerar para ello los recursos y la situación del niño y de las personas responsables de proveerlos. Es que, frente a la naturaleza prestacional del derecho a la salud de las personas con discapacidad, la respuesta estatal debe traducirse necesariamente en un hacer, en tanto es a él -como autoridad pública- a quién le incumbe el deber impostergable de garantizar su efectivización mediante el dictado de acciones positivas. Ello sin perjuicio de las obligaciones que deban asumir en su cumplimiento las jurisdicciones locales, las obras sociales o las entidades de la llamada medicina prepaga.

\section{La tutela judicial efectiva del menor con discapacidad a través de la cautelar innominada.}

Conforme la normativa referenciada, queda claro que corresponde al Estado -como principal obligado-, brindar la tutela judicial efectiva a los fines de efectivizar el derecho a la salud, a una buena calidad de vida y a brindar una asistencia médica adecuada, principalmente, si se está en presencia de sujetos vulnerables. ${ }^{9}$

En el racconto de la situación vital que atraviesa el menor con discapacidad, se mencionan las distintas deficiencias que padece y la necesidad de ser sometido a una intervención quirúrgica -con sus posteriores tratamientos de rehabilitación y medicación- a los fines alcanzar una calidad de vida digna.

No obstante, para garantizar estos derechos se requiere de una tutela que anticipe su reconocimiento de manera efectiva e inmediata. Y es en este punto donde se destaca la importancia que tiene la "medida cautelar" como vía para neutralizar la urgencia y dar respuesta oportuna a la situación planteada.

El proceso cautelar ha sido definido como "aquel que tiende a impedir que el derecho cuyo reconocimiento o actuación se pretende obtener a través de otro proceso, pierda virtualidad o eficacia durante el tiempo que transcurre entre la iniciación de ese proceso y el pronunciamiento de la sentencia definitiva"10.

Se ha expresado (Zalazar, 2011;180) que la medida cautelar "es aquella que tiende a alte-

\footnotetext{
9 La Corte Interamericana de Derechos Humanos en autos "Furlan, Sebastián y Familiares c. Argentina" del 31/8/2012, sostuvo que... “Toda persona que se encuentre en una situación de vulnerabilidad es titular de una protección especial....

10 Palacio, Lino E. “Manual de Derecho Procesal Civil”, Ed. Abelado Perrot, Buenos Aires, 1998, 14. e ed. Pág. 773-774.
} 
rar el estado de hecho existente antes de la petición de su dictado. Es decir que la misma, efectivamente altera la situación imperante y en otros casos va más allá "creando" una situación nueva o distinta a la existente". ${ }^{11}$

La finalidad de toda medida cautelar consiste en evitar que se tornen ilusorios los derechos de quien los solicita, ante la posibilidad de que se dicte una sentencia favorable. Es decir, se trata de sortear la posible frustración de los derechos de las partes a fin de que no resulten inútiles los pronunciamientos que den término al litigio ${ }^{12}$.

El caso en estudio, se trató -precisamente- de un pedido de cautelar innominada configurativa de "tutela anticipada parcial", para quién invocó y acreditó la calidad de persona menor discapacitada.

En este contexto, la doctrina ha señalado que "la referida tutela anticipada se motoriza mediante el despacho de una cautelar innovativa a la que se le reconoce idoneidad para adelantar -siempre y cuando concurran plurales y exigentes recaudos-, la satisfacción de lo pretendido por la actora sin que ésta todavía hubiera obtenido una cosa juzgada favorable ${ }^{\prime \prime 13}$.

Asimismo, el anticipo de jurisdicción que le incumbe a los tribunales al examinar ese tipo de medidas cautelares, jamás importa una decisión definitiva sobre la pretensión concreta del demandante pero sí lleva ínsita una evaluación del peligro de permanencia en la situación actual que padece el menor discapacitado. Es decir, el otorgamiento del despacho cautelar, en nada afecta al fondo de la cuestión, cuya consideración en su totalidad solo podrá ser efectuada una vez concluido con el proceso principal.

En este marco, la Cámara no paso por alto que, este tipo de remedio implicaba una decisión excepcional, pues alteraba el estado de hecho o derecho existente al tiempo de su dictado, y como configuraba un anticipo de jurisdicción favorable respecto del fallo final de la causa, justificó una mayor prudencia al apreciar los requisitos de procedencia de la medida cautelar.

Así, el primer requisito que analiza el tribunal es la "verosimilitud del derecho", que se entiende como la posibilidad de que el derecho invocado exista, que tenga apariencia de verdadero, por lo que debe ser examinado con mayor rigor cuando con la cautelar se persigue la tutela anticipada del derecho que constituye el objeto del amparo. Por consiguiente, la cautelar no se puede ordenar si previamente no se acredita al menos en ese grado de apariencia, que se ha vulnerado el derecho del menor discapacitado.

Ahora bien, la jurisprudencia ha considerado que "estando en juego derechos humanos fundamentales tales como el derecho a la vida y a la integridad física, la verosimilitud del derecho, como requisito de la medida cautelar, se refiere a la posibilidad de que el derecho exista y no a una incontestable realidad que sólo se logrará al agotarse el trámite procesal del juicio respectivo. El análisis e interpretación de la pretensión debe ser flexible, en tanto no se trata de una cuestión crematística o patrimonial"14. Es que, si bien

11 Zalazar, C. E. (2011): Guía práctica para el ejercicio del derecho: Civil y Comercial", Tomo I,- año 2011, Ed. Advocatus. P. 180. 12 Cfr. CFAMdP en autos “Antonio Barillari SA c/ Medida Cautelar Autónoma”, sentencia registrada al T. ${ }^{\circ}$ CX F. ${ }^{\circ} 15689$; entre otros. 13 Peyrano, Jorge W. (2010), Tendencias pretorianas en materia cautelar. Ed. Rubinzal Culzoni, Santa Fe, T. I. pág. 68. 14 CNFed. Civ. y Com., Sala III, 28/8/2008, “Stegman, Brian Gunther Oscar c/ Dirección de Ayuda Social para el Congreso de la Nación”, DJ, $2003-3-1181$. 
estamos ante una medida cautelar de carácter excepcional no debemos perder de vista que, en casos como el presente en donde el objeto último de la acción está dirigido a la protección de la salud de una persona menor con discapacidad, esa exigencia debe ser menos rigurosa que en otros, dadas las consecuencias dañosas que podría traer aparejada la demora en satisfacer la prestación tal como la que se reclama.

A su vez, dicha medida se halla condicionada también a que el interesado acredite la existencia del peligro en la demora.

Este requisito debe ser analizado por el juzgador en forma objetiva y teniendo en cuenta la documentación aportada por el amparista, quien debe acreditar: condición de vida del menor discapacitado; que la falta de cobertura de las prestaciones reclamadas pone en riesgo la salud del menor; la necesidad de que se dé continuidad a los tratamientos peticionados para alcanzar una calidad de vida digna; y, además, debe existir temor de que en caso de no otorgarse la tutela requerida, el estado de cosas actual derive en un daño irreparable para el niño.

En un caso semejante al de análisis, la CSJN precisó que “...el peligro en la demora aparece en forma objetiva en tanto la situación de discapacidad y la necesidad de cuidados que la peticionaria padece requiere el dictado de decisiones que resguarden los derechos por ella invocados hasta tanto exista la posibilidad de dirimir los puntos debatidos y de esclarecer los derechos que cada una de las partes aduce"15.

En tal línea también se expresado que "no debe perderse de vista la perspectiva de la vulnerabilidad bajo cuyo prisma debe ensayarse cualquier salida jurisdiccional vinculada con personas en situación de vulnerabilidad; esto es, personas que, por razón de su edad, género, estado físico o mental, o por circunstancias sociales, económicas, étnicas y/o culturales, encuentran especiales dificultades para ejercitar con plenitud ante el sistema de justicia los derechos reconocidos por el ordenamiento jurídico (100 Reglas de Brasilia sobre Acceso a la Justicia de las Personas en Condición de Vulnerabilidad, sección segunda, 1.3)". ${ }^{16}$

\section{Resolución de la Cámara Federal de Apelaciones.}

La Cámara Federal de Apelaciones de la ciudad de Mar del Plata al analizar si se encontraban cumplidos los requisitos para la procedencia de la medida cautelar en el caso planteado, resolvió rechazar la apelación interpuesta, y en consecuencia, confirmar la medida cautelar dispuesta por el tribunal de grado.

En relación al "fomus bonis iuris" indicó que en principio se encontraba acreditado, toda vez que de las constancias del expediente, surgía a "prima facie" que la amparista era afiliada a la obra social demandada y, además, del certificado que se acompañó surgía el diagnóstico y necesidad de realizar la cirugía requerida.

Respecto al agravio empleado por la apelante relativo al establecimiento donde debía llevarse a cabo la cirugía, el tribunal tuvo en cuenta lo manifestado por el médico de cabecera menor, quién sugirió que se realice en el nosocomio donde el niño es atendido, por tratarse de un centro especializado en cardiología infantil. 
En virtud de ello, y teniendo en cuenta el diagnóstico del niño, la Cámara sostuvo que se debía preservar -y garantizar-, la relación médico paciente que se había gestado con los profesionales de esa institución, sin perjuicio de lo que, con posterioridad, se resuelve en la sentencia definitiva; máxime cuando la terapia del niño ya había tenido principio de ejecución en dicho nosocomio. En consecuencia, rechazó el agravio de la accionada.

En relación al peligro en la demora, el tribunal estimó que el perjuicio era inminente y que respondía a una necesidad efectiva y actual, y que ante la posibilidad de que el accionante triunfe en su reclamo, la revocación de la medida cautelar decretada le ocasionaría al menor un perjuicio que se tornaría irreparable o al menos de difícil solución ulterior, ya que resultaría imposible subsanar una circunstancia que deviene agotada por el transcurso del tiempo. Asimismo, resaltó que el anticipo de jurisdicción en las medidas cautelares innovativas no importaba prejuzgamiento ${ }^{17}$.

\section{Conclusiones}

En el caso traído a consideración en este comentario, se debatieron derechos tan fundamentales como son la vida y la salud de un menor en condiciones de vulnerabilidad que estaba necesitado de una urgente tutela de sus derechos.

Del análisis de la cuestión, surgieron acreditados los requisitos que permitieron al tribunal interviniente confirmar la medida innovativa. Por un lado, existía verosimilitud en el derecho pues se encontraba acreditada la afección padecida por el menor con discapacidad y, por el otro, se configuraba el peligro en la demora, ya que de no brindar al niño la intervención quirúrgica, el tratamiento posterior y rehabilitación indicados por los profesionales especializados en cardiología infantil, podría haberse agravado su estado de salud e integridad física poniendo en riesgo su vida.

Desde esa óptica, comparto y celebro el criterio de la Cámara que bregó por la adopción de medidas tendientes a efectivizar el derecho a la salud de un menor vulnerable, y asegurarle, de este modo, lo indispensable para el desarrollo de una calidad de vida digna. Esto implica alcanzar las mejores condiciones para que ese niño que atraviesa graves padecimientos de salud pueda vivir en la más amplia plenitud posible teniendo principalmente en mira su interés superior. Es que, no debemos perder de vista que en todas las decisiones que involucren a niños y niñas, su interés superior deberá ser la consideración primordial.

Asimismo, se impone hacer notar que la medida cautelar -en este caso- tuvo como principal finalidad resguardar los derechos fundamentales de una persona vulnerable, y donde cobraron preponderancia los beneficios concretos que la cirugía y el tratamiento posterior -realizados en el lugar y con los profesionales que cuentan con la especialidad y equipamiento necesario para ello- podían producirle en la salud al menor.

No obstante, se debe tener presente que frente a planteos que vislumbren una situación crítica y se presente duda sobre la forma resolverlos, siempre se debe estar por el principio "pro homine", que implica dar primacía del mejor derecho a favor del individuo, lo que impone privilegiar la decisión que garantice el tratamiento que demuestre efectivo progreso en la salud y calidad de vida del vulnerable. 
Todas estas reflexiones resultan suficientes para destacar la labor del tribunal que emitió una solución congruente y acorde con la urgencia ínsita en el planteo. En definitiva, hizo efectivo el derecho de un niño que se encontró en una situación de extrema vulnerabilidad y que acudió imperiosamente al órgano judicial para resguardar sus derechos personalísimos y básicos, como lo son la vida y la salud.

\section{REFERENCIAS BIBLIOGRÁFICAS}

- Andruet, A. S.; (2000): Código de Ética para las Magistraturas Provinciales. Revista de la Asociación de Magistrados y Funcionarios de la Justicia Nacional, n. 25 (enero-julio), Bs. As., Regla 304, pág. 86.

- Peyrano, Jorge W. (2010), Tendencias pretorianas en materia cautelar. Ed. Rubinzal Culzoni, Santa Fe, T. I.

- Feito, L. (2007): Vulnerabilidad. Anales del Sistema Sanitario de Navarra. ISSN 11376627. Disponible en: http://scielo.isciii.es/scielo.php?script=sci_arttext\&pid=S113766272007000600002\#bajo

- Palacio, L.E. (1998): Manual de Derecho Procesal Civil, Ed. Abelado Perrot, Buenos Aires, ed. $14 .^{\circ}$.

- Peyrano, J. W., (2018): Lo urgente y lo cautelar: diferencias y coincidencias. SJA 13/2/2019, 3. JA 2019-I,3. Cita online: AR/DOC/3760/2018.

- Zalazar, C. E. y Carranza, G. G. (2019): Derecho y Salud en Perspectiva. Estudios de Derecho a la Salud. Córdoba. Ed. Advocatus.

- Zalazar, C. E. (2011): Guía práctica para el ejercicio del derecho: Civil y Comercial. Tomo I. Córdoba. Ed. Advocatus. 